\title{
EHMTI-0145. Health risk behaviours in medication-overuse headache: results of a population-based study
}

\author{
M Westergaard ${ }^{1 *}$, C Glümer², E Holme Hansen ${ }^{3}$, RJ Jensen ${ }^{1}$ \\ From 4th European Headache and Migraine Trust International Congress: EHMTIC 2014 \\ Copenhagen, Denmark. 18-21 September 2014
}

\section{Introduction}

Medication-overuse headache ( $\mathrm{MOH})$ has been called a biobehavioural disorder.

\begin{abstract}
Aim
In this cross-sectional study, we investigated associations between $\mathrm{MOH}$ and health-related behaviours as indicated by daily smoking, physical activity, and body mass
\end{abstract} index.

\section{Methods}

129,150 randomly selected individuals aged $>16$ years were given self-administered questionnaires on general health, headache frequency, over-the-counter (OTC) analgesic use, and health behaviour. Respondents with chronic headache ( $>15$ days/month over three months) with concurrent over-the-counter analgesic intake of $>15$ days/month were classified as having MOH. Associations between $\mathrm{MOH}$ and health behaviours were analyzed by logistic regression controlled for sociodemographic factors. All analyses were adjusted for stratified sampling and non-response.

\section{Results}

There were 68,518 respondents. Among the 1,082 people with $\mathrm{MOH}, 34.2 \%$ were daily smokers, $48.4 \%$ were physically inactive, $57.7 \%$ were overweight/obese, and $72.0 \%$ had at least one of these three health risk factors. The group with $\mathrm{MOH}$ was significantly different from all other respondents in terms of prevalence of these factors $(\mathrm{p}<0.0001)$. MOH was significantly associated with daily smoking (odds ratio [OR] 1.5), physical inactivity
(OR 1.8), and obesity (OR 1.7). Having all three health risk factors was even more strongly associated with $\mathrm{MOH}$ (OR 3.1 in women and OR 5.5 in men).

\section{Conclusion}

Unhealthy lifestyle may be a modifiable risk factor for headache chronification and medication overuse. Health behaviour counseling should be part of $\mathrm{MOH}$ management.

No conflict of interest.

\section{Authors' details}

'Department of Neurology, Danish Headache Center, Glostrup, Denmark. ${ }^{2}$ Glostrup Hospital, Research Center for Prevention and Health, Glostrup, Denmark. ${ }^{3}$ Department of Pharmacy, Faculty of Health and Medical Sciences University of Copenhagen, Copenhagen, Denmark.

Published: 18 September 2014

\section{doi:10.1186/1129-2377-15-S1-B38}

Cite this article as: Westergaard et al:: EHMTI-0145. Health risk behaviours in medication-overuse headache: results of a populationbased study. The Journal of Headache and Pain 2014 15(Suppl 1):B38. 